\title{
INFIDELIDADE MASCULINA E VIOLÊNCIA DOMÉSTICA: VIVÊNCIA DE UM GRUPO DE MULHERES*
}

\author{
MASCULINE INFIDELITY AND DOMESTIC VIOLENCE: EXPERIENCE OF A \\ GROUP OF WOMEN
}

\section{INFIDELIDAD MASCULINA Y VIOLENCIA DOMÉSTICA: LA EXPERIENCIA DE UN GRUPO DE MUJERES}

\author{
RUTH FRANÇA CIZINO DA TRINDADE**, ANA MARIA DE ALMEIDA***, \\ CÉLIA ALVES ROZENDO****
}

\begin{abstract}
RESUMO
Este artigo tem como objetivo apresentar a experiência de mulheres na relação vivida com seus parceiros, cuja natureza do estudo foi qualitativa. Participaram 14 mulheres na faixa etária de 20 a 24 anos, residentes na periferia de Maceió, capital do estado de Alagoas. A coleta de informação foi realizada por meio de entrevistas, utilizando gênero como referencial teórico e a história oral temática como procedimento metodológico. A gravidez ocorrida na adolescência propiciou a união consensual, quando ela não existia anteriormente, com exceção de uma das participantes. Porém nesta união alguns homens agiam mais livremente, mantendo relações extraconjugais e chegavam a agredir suas mulheres, em casa. A maioria das mulheres convive com o problema da infidelidade masculina e da violência doméstica, que é acrescido das circunstâncias de dificuldade de sobrevivência. No exame de suas histórias observamos que elas consideram errada a atitude do parceiro, de trair e agredir, mas a maioria se submete a tomarem conhecimento e terem reações passivas, ou queixas que geram brigas entre o casal, porém que não garante a modificação de comportamento do mesmo e a sua integridade física e psicológica. Essa situação revela a dominação masculina exercida nas relações entre os sexos, caracteriza as assimetrias de gênero que permeiam as relações conjugais, no grupo estudado, e dá visibilidade à posição de submissão a que essas mulheres estão sujeitas.
\end{abstract}

Palavras chaves: Identidade de gênero, feminismo, violência doméstica, infidelidade

*APOIO - CAPES, e CNPq

**Enfermeira, Professora Doutora da Escola de Enfermagem e Farmácia da Universidade Federal de Alagoas. Email: ruth trindade@yahoo.com.br. Av. Lourival Melo Mota s/n - Campus A.C. Simões - CEP 57072-970 Maceió/AL -Brasil

***Enfermeira. Professora Doutora do Departamento de Enfermagem em Saúde Pública e Materno Infantil da Escola de Enfermagem de Ribeirão Preto/Universidade de São Paulo. Email: amalmeid@eerp.usp.br . Av. Bandeirantes no. 3900, CEP. 14040-902. Ribeirão Preto/SP-Brasil

${ }^{* * * *}$ Enfermeira, Professora Doutora da Escola de Enfermagem e Farmácia da Universidade Federal de Alagoas. Email: celia.rozendo@gmail.com . Av. Lourival Melo Mota s/n - Campus A.C. Simões - CEP 57072-970 Maceió/AL -Brasil 


\section{ABSTRACT}

This article's objective is to present the experience of women in their daily relationship with their partners, in a qualitative study. There were 14 women participating age between 20 to 24 years old, they all lived in the outskirts of Maceio, capital of Alagoas state. Data collection was done through interviews, using gender as the theoretical reference and oral history as the thematic methodologic procedure. The pregnancy occurred during adolescence and it was provided a consensual union, when it did not exist before, except for one of the participants. But in this kind of union, some men acted more freely, having extramarital relations and many times attacking their wives at home. Most women live with the problem of male infidelity and domestic violence, that increases with poverty. As we read their histories, we notice that they consider wrong their partner attitude of betraying and harming, but most of them have passive reactions when they know about, or when they complaint, it generates fights between the couple, but it does not modify men's behavior and it doesn't grant women's physical and psychological integrity. This situation shows the male domination exerted in gender relations, it characterizes the gender asymmetries that permeate the couple relations, and gives visibility to the submission position to which these women are exposed, in this study.

Key words: Gender identity, feminism, domestic violence, infidelity

\section{RESUMEN}

El presente estudio, de carácter cualitativo, tuvo como objetivo presentar resultados de la experiencia de mujeres en la relación con sus parejas, en su condición de madres y esposas. Participaron 14 mujeres con edad entre 20 y 24 años, residentes en las afueras de Maceió, capital del estado de Alagoas, Brasil. La información se obtuvo a través de entrevistas, utilizando el género como una referencia teórica y la historia oral como un procedimiento temático metodológico. El embarazo ocurrido en la adolescencia determino la unión consensual, a excepción de una de las participantes que ya había contraído matrimonio. No obstante, ante esta unión algunos hombres actuaban con mayor libertad, manteniendo relaciones extraconyugales, y llegaban a agredir a sus esposas en el hogar. La mayor parte de las mujeres convive con el problema de la infidelidad masculina y de la violencia doméstica, que resulta agravado por las circunstancias que dificultan la sobrevivencia. El examen de sus relatos refleja que consideran equivocada la actitud de su compañero, al traicionarlas y agredirlas fisicamente, pero la mayoría se somete y adopta un comportamiento pasivo, o expresa sus quejas generando nuevas discusiones y agresiones en la pareja, lo cual no contribuye a modificar el proceder del hombre, ni a preservar la integridad física y síquica de la mujer. Esto revela la dominación masculina ejercida en las relaciones entre ambos sexos, y caracteriza las asimetrías de las relaciones de género presentes en el matrimonio, reflejando las condiciones de sumisión a las que están expuestas estas mujeres.

Palabras claves: Identidad de género, feminismo, violencia doméstica, infidelidad.

Fecha Recepción: 05 abril 2006 Fecha Aceptación: 02 septiembre 2008

\section{INTRODUÇÃO}

A abordagem das relações de gênero envolvendo a infidelidade masculina e a violência doméstica, a partir de uma perspectiva das mulheres que a vivenciaram, pode se tornar uma área de estudo bastante promissora, pois além de identificar a problemática e as limitações vividas por elas, pode revelar as desigualdades de gênero nesta relação. Através deste estudo identificamos a quase inexistências de estudos sobre infidelidade mostrando a importância e relevância do mesmo para os estudos de gênero, pois o mesmo é pouco explorado. Este artigo é parte de uma pesquisa mais extensa, para tese de doutorado defendido em 2005. Neste artigo esta sendo apresentado à experiência de mulheres na relação vivida com seu parceiro. 
Rosalvo (1979) sugere que a desigualdade universal dos papéis sexuais provavelmente seja o resultado de um conjunto de diferentes fatores, envolvidos no estabelecimento das sociedades. Para a autora, parece que uma "análise das forças nos sistemas sociais humanos e da organização das famílias humanas, em particular, propiciará resultados muito promissores" no entendimento e busca de superação das desigualdades.

Em muitas sociedades, ditas tradicionais, uma grande parte da vida adulta da mulher é gasta na geração e criação dos filhos. Isso leva à diferenciação das dimensões doméstica e pública, sendo suas atividades restritas aos cuidados com os filhos e o enfoque de suas emoções e a atenção são voltados para os filhos e o lar, sendo as mulheres absorvidas principalmente em atividades domésticas devido a este papel (Rosalvo, 1979).

Badinter (1993) afirma que a transformação do mundo traz à tona as diferenças da masculinidade, sobretudo agora que, em nossos países, vemos como o poder que lhes servia de proteção desmorona. Sem suas defesas milenares, o homem expõe abertamente suas feridas.

Quando se discute a violência, encontramse vários conceitos que tentam definir este fenômeno. Existe uma definição bastante aceita por ser abrangente e que trata a violência como "a ruptura de qualquer forma de integridade da vítima: integridade física, integridade psíquica, integridade sexual, integridade moral" (Saffioti, 2004).

A violência contra a mulher se configura, como uma questão cultural, política, jurídica e principalmente de saúde, sendo a infidelidade uma forma de violência. $O$ Estado Brasileiro reconhece que necessita de empreender uma ação firme e coordenada com os estados e municípios criando, então, uma política de enfrentamento à violência contra a mulher, a qual se propõe a atuar junto à prevenção, ao atendimento multidisciplinar em rede e à ampliação do acesso das mulheres aos serviços de Justiça e Segurança Pública (Secretaria
Especial de Politicas para as Mulher, 2006 ), tendo sido sancionada em 07 de agosto de 2006 a Lei Maria da Penha no 11.340/06, que entrou em vigor no dia 22 de setembro do mesmo ano, a mesma propõe a proibição da aplicação de penas pecuniárias (cestas básicas e multas) e institui juizados especiais com competência cível e criminal .

Entendemos que os estudos sobre a infidelidade, violência doméstica e as relações de gênero são importantes e que os mesmos poderão contribuir para a Enfermagem compreender melhor as vivencias individuais das pessoas de quem cuidam e convivem profissionalmente, assim como para outras profissões que trabalham com esta questão.

\section{MATERIAL E METODO}

A história oral temática foi o procedimento metodológico aplicado nessa investigação. Como técnica de coleta de informações acerca da história oral das mulheres estudadas, utilizamos a entrevista já preconizada como instrumento de eleição para colher a história oral. Como assinala Thompson (1998), "uma entrevista não é um diálogo, ou uma conversa. Tudo o que interessa é fazer o informante falar".

O local onde realizamos o estudo situa-se na área vicinal do Campus da UFAL, uma das regiões periféricas da cidade de Maceió, formada por conjuntos residenciais atendidos por uma unidade da estratégia saúde da família.

O Projeto foi aprovado pelo CEP - Comitê de Ética em Pesquisa da Escola de Enfermagem de Ribeirão Preto da Universidade de São Paulo, e encontra-se registrado no protocolo número 0308/2002.

A coleta de dados foi realizada após o consentimento verbal e escrito por meio de assinatura, em duas vias, do Termo de Consentimento Livre e Esclarecido.

A seleção das mulheres para participarem do estudo foi intencional, fazendo parte dela 
14 mulheres de classes sociais com baixo nível sócio-econômico que atendiam aos critérios de inclusão, ou seja, com idade entre 20 e 24 anos, formando um grupo geracional.

Neste estudo, optamos pela entrevista por pauta, pois apresenta um certo grau de estruturação, caracterizada pela preparação de guia de temas a tratar, ou seja, uma relação de pontos de interesse que o entrevistador vai explorando ao longo da entrevista, sendo a pauta de nossa entrevista sua vida como esposa/companheira e mãe.

As entrevistas transcorreram de uma maneira bastante amigável, com a interferência da pesquisadora na condução do depoimento, através de perguntas encadeadoras a partir das declarações das depoentes. Foi necessário, durante as entrevistas, usar técnicas de incentivo para com as nossas colaboradoras tais como: silêncio, animação e elaboração de perguntas, reafirmação e repetição de respostas e mudança de tema.

A natureza desta pesquisa foi qualitativa, tendo em vista seu objeto de estudo e objetivo proposto, que buscou apreender “(...) o universo de significados, motivos aspirações, crenças, valores e atitudes" que "não podem ser reduzidos à operacionalização de variáveis" (Minayo, 2000).

$\mathrm{Na}$ análise do material recolhido buscou-se atingir a três objetivos: a) ultrapassagem da incerteza; b) enriquecimento da leitura; c) integração das descobertas. A interpretação dos resultados se deu tendo como referência as falas das mulheres colaboradoras desta investigação, a partir das suas histórias orais temáticas em abordavam a temática do estudo, ou seja, a infidelidade. Nesse processo tornouse necessário fragmentá-las, assim recortamos as passagens que diziam respeito aos objetivos do estudo.

As etapas deste processo foram: 1 . Transcrição das entrevistas gravadas em fitas. 2. Conferência das transcrições com as fitas gravadas. 3. Complementação do conteúdo das entrevistas através dos registros do diário de campo. 4. Estabelecimento de contato com o material através da leitura do conteúdo. 5 . "Re-construção" do texto.

\section{RESULTADOS}

Segundo Gomes, Diniz, Araujo e Coelho (2007) as relações familiares são permeadas por relações de poder, nas quais as mulheres, como também as crianças, obedecem ao homem, tido como autoridade máxima no núcleo familiar. Assim sendo, o poder do homem é socialmente legitimado, seja no papel de esposo, seja no papel de pai.

Todas as mulheres entrevistadas, em um total de quatorze (14), tiveram a experiência de viverem em união consensual com um parceiro, apenas uma a formalizou a união com um casamento civil.

À escolaridade delas variou de analfabetas a oitava serie. No momento da entrevista uma continuava com os estudos. Apenas duas das mulheres entrevistadas tinham atividade que lhes geravam renda, uma vendia roupas de cama em domicílio e outra fazia faxina em uma residência. Todas as outras tinham o seu parceiro ou pai de seus filhos como provedores da família.

No momento da entrevista cinco das mulheres estavam separadas de seus parceiros. Das 14 mulheres, oito fizeram referência a terem tomado conhecimento da traição de seus parceiros entre elas seis sofreram agressões físicas.

\section{Infidelidade masculina e violência doméstica}

As mulheres fizeram queixas de sua falta de liberdade e de ressentimento pela atitude do parceiro, que as trai e as agride e elas se vêem, muitas vezes, impossibilitadas de reagir e modificar a situação. Badinter (2004) afirma que a dominação masculina baseia-se no poder dos homens em tratar as mulheres como objetos sexuais. 
De acordo com Salem (2004), a sexualidade masculina pode ser representada em termos de uma teoria sexual pulsional, tendo em vista o desejo incontrolável que o homem tem de transar, ligado à "vontade" de fazer sexo. Segundo a autora, a traição masculina prevê simultaneidade de vínculos com diferentes parceiras, fato creditado "à dificuldade masculina de resistir aos apelos das numerosas (...) parceiras sexuais que afirmam haver tido ao longo da vida" (Salem, 2004).

De acordo com a autora, "a quase vocação masculina para a 'traição' é justificada ora com base na 'vontade' sexual incontrolável, ora no descompasso, também naturalmente fundado, entre suas 'necessidades' sexuais e as da parceira fixa" (Salem, 2004). As explicações têm se fundamentado na naturalização dessa condição apontando que o homem trai impulsionado por essa pulsão sexual que o subjuga a responder aos sinais do seu corpo, justificando-se com o argumento de que a 'carne é fraca'. A traição da mulher, entretanto é vista como um ato de "intencionalidade, de um ato de vontade deliberado e controlável" (Salem, 2004), portanto condenável.

Assim, socialmente, temos um duplo padrão de moralidade e normas para a (in) fidelidade, os homens podem trair, porém suas mulheres não. Baseado nessas concepções é que parece residir a aceitação ou resignação que algumas mulheres demonstraram ao relatar a traição de seus companheiros.

Apesar de Bonzon (1998) reconhecer que as trajetórias conjugais atualmente vêm sofrendo modificações ao longo da história e, existem modificações no papel da mulher com uma esperada modificação de sua sexualidade. Observamos entre as jovens mulheres estudadas um padrão em que o homem exerce um papel mais autônomo no exercício de sua sexualidade e a mulher se subordina a essa conduta masculina reconhecida como parte de sua natureza. Entretanto observamos que, ao se subordinarem a essa situação, não significa que elas a aceitem como natural, mas em suas narrativas demonstram a impossibilidade de agir devido à dependência econômica que têm dos mesmos.

$\mathrm{Na} 2^{a}$ gravidez, sempre ele tinha as andada dele fora de casa à noite, quando foi depois ele contou que tava com um caso com outra pessoa. A minha reação foi mudar muito com ele, por causa dele, uma pessoa que tem compromisso não podia fazer isso. Porque se o homem tem a sua mulher em casa não devia arrumar outra fora, principalmente quando a gente não convive na casa da gente mesmo [...] Quando eu falava, ele reagia com muita ignorância, queria ser maior que eu, mas pela vontade dele mesmo, depois que ele ficou mais velho um pouco ai ele parou de fazer isso.

Bonzon (1998) admite que os comportamentos e as experiências de homens e mulheres no que se refere à sexualidade configuram-se como uma das maneiras de dominação de um sobre o outro. A infidelidade, de certa forma, pode representar subjugação da mulher, visto que para muitas delas uma separação poderia significar a perda das condições mínimas em que vivem.

Sobre o papel masculino na relação sexual, Foucault (2001) afirma que ao homem cabe a função ativa e a mulher fica com o papel passivo de receptora nesta relação, sendo dados valores e funções distintos sobre quem exerce o papel de domínio nesta relação e a quem cabe ser dominado. A traição e a agressão, muitas vezes, parecem ser as formas como os homens exercem essa relação de dominação, enfatizando a sua liberdade no exercício da sua sexualidade e não aceitando oposição à mesma, subordinando a mulher a sua conduta sem que a mesma reaja de uma maneira mais efetiva, contra a situação a que é submetida pelo companheiro.

A violência contra a mulher ganhou visibilidade na década de 1980 , através da luta feminista, seguida posteriormente por intervenções no âmbito legal e judiciário. A maioria das denúncias de agressões ocorre dentro das relações conjugais (Gregori, 1999). A violência doméstica contra a mulher constróise a partir das relações de desigualdade 
entre homens e mulheres, sendo naturalizada no processo de socialização dos sujeitos e reproduzida de geração a geração.

Entre as mulheres estudadas, existe uma dualidade na interpretação da violência, o que pode ser visto a partir da narrativa que uma das mulheres faz do comportamento de seu parceiro: (...) ele não é uma pessoa agressiva comigo. Ele é um pouco grosso (...) porque sempre que ele bebe fica muito enjoado, não tem muita paciência, é só este o problema dele".

Uma não aceita agressão e procura revidar, dizendo: "Como mulher eu gosto muito da minha casa, do meu marido, agora ultimamente passei por um sufoco muito grande, tô passando, que meu marido agora se enganchou com outra na rua, tira do pouco que a gente tem para dar a essa da rua (...) Quando ele está bom ele é uma pessoa, mas quando bebe! Aí dana-se a ficar bravo comigo, querendo quebrar as coisas, eu também não deixo, não vou deixar ele quebrar as coisas, ele vem dar em mim, eu vou e dou nele também".

Outra relaciona a agressão com o álcool: "Ele chegou em casa tarde, bêbado, aí a gente brigou, discutiu, aí os vizinhos vieram tirar a briga da gente. (...) É horrivel, a fase mais ruim da minha vida eu acho, porque ser traída como eu já fui dentro de casa mesmo, quando deixava uma pegava outra. Ele chegou até namorar de porta com uma menina, ia noivar e tudo e eu aqui sem saber não, nas minhas gravidez ele tava me traindo aí foi a fase mais difícil, pra mim a traição é a pior coisa do mundo. Foi o momento mais horrivel. (...) ele já bateu em mim três vezes quando tava bêbado".

A violência conjugal a que essas mulheres estão submetidas está relacionada ao uso abusivo de álcool e à traição, comportamentos socialmente permissivos ao homem, e contra os quais as mulheres não encontram apoio para lutar contra eles.

A violência doméstica, entre esses casais, muitas vezes, caracterizou-se com lesões corporais, porém nenhuma delas fez qualquer denúncia na justiça contra seus parceiros, demonstrando comportamentos passivos e esperando que estas agressões parassem naturalmente, o que demonstra que as relações têm se baseado nas assimetrias de gênero, quando identificamos a passividade com que elas reagem à agressão.

Gregori (1999), analisando denúncias em delegacias de mulheres, verifica que elas não estavam interessadas em punir ou processar seus parceiros, mas sim serem ressarcidas pelas perdas morais ou materiais e principalmente esperavam que seus maridos deixassem de agredilas.

Para a autora, esses relacionamentos violentos "revelam com intensidade que a agressão funciona como uma espécie de ato de comunicação, nos quais diferentes matizes podem estar atuando" (Gregori 1999). Ela continua afirmando que estas relações "evidenciam, sobretudo, que o problema principal das questões de gênero está na assimetria entre as partes".

A violência doméstica relatada pelas mulheres do estudo demonstra a existência de relacionamentos conflitivos vividos por elas, com agressões físicas e verbais freqüentes, para as quais elas não buscam ajuda externa, mas as deixam revoltadas, como afirma uma das mulheres: Já apanhei devido a ter sido traída, não tem condições de uma mulher ainda amar um homem, ela pode gostar porque é pai dos filhos, mesmo sendo pai dos filhos não tem condição, esta semana tive uma briga muito feia com ele. Um pai de família que só entra em casa para brigar (...) eu fiquei muito revoltada, tive vontade de sair de noite, deixar casa, deixar filho, deixar tudo para ele (...).

A vida delas é permeada de muito sofrimento sem muitas alternativas de melhora, e as infidelidade e agressões têm se caracterizado como forma de dominação masculina que se configura, nesse grupo, e se mantém porque as mulheres estão confinadas ao espaço doméstico, não visualizando alternativa para sair dessa situação. Coabitar é uma situação propícia para o surgimento de conflitos que nem todos os casais têm condições de resolver de maneira amigável e madura. 
A maioria destas uniões surgiu da necessidade de dar um caráter de aceitabilidade social às gravidezes não planejadas pelo casal e, com o passar dos anos, os homens passam a questionar que as mesmas lhes tiraram a liberdade e aumentaram sua carga de responsabilidades frente à sobrevivência de sua família. Em meio a grandes adversidades e não encontrando apoio social para lidar com essas situações, encontram na infidelidade uma forma de fugir das responsabilidades do cotidiano, mesmo que tenha conseqüências para o relacionamento.

A separação em alguns casos foi a alternativa para a solução dos conflitos, como nos mostram as histórias de vida. A decisão por uma separação, na maioria dos casos, foi tomada pela mulher, mostrando sua capacidade de sair de situações que não mais satisfazem a suas necessidades afetivas, enfrentando o ônus da sua resolução. Em dois casos, esta decisão foi tomada considerando sua insatisfação com a situação vivida. A seguir, vemos um relato sobre a separação: $A$ gente ficou oito anos juntos, separamos agora a pouco, no Natal. (...). hoje em dia eu estou separada, arcando com as conseqüências. (...) acho que estou aprendendo a encarar a vida, lutando pra conseguir e tenho fé em Deus que eu vou conseguir. (...) estou encarando a vida como ela é, de frente sem medo de ser feliz, sem medo de encarar. (...) se for pra viver sozinha mesmo tendo só essa preocupação e dificuldade, a viver ao lado de um homem e não ter sossego, nem a paz, eu prefiro ficar só, porque não adianta nada você morar com uma pessoa só por bens materiais e você não ter a sua paz. Eu pelo menos me preocupo com as coisas dentro de casa, mas eu tenho a minha paz, tenho o meu sossego, graças a Deus to vivendo bem.

Outra narra a vontade que têm de se separar de seu parceiro, mas não encontra condições propícias para isso: Que nem eu falo para ele, eu disse a ele, se ele não melhorar eu vou viver a minha vida; e ele vai viver a dele. Ele disse que eu com três filhos não posso viver como uma pessoa normal. Posso. Só trabalhar e arrumar uma pessoa pra deixar meus filhos. Minha vida não é boa por causa disso, mas que eu vejo tantas mães que têm cinco e seis filhos e vive bem.

Uma das mulheres decidiu se separar porque queria sua liberdade de volta: A gente ainda viveu três anos, (...) eu resolvi me separar. Aí eu fui embora, vim embora pra casa da minha mãe e não quis mais saber. Eu estava cansada de todo mundo poder se divertir e eu sempre ficar ali em casa, eu não tava agüentando mais aquela situação de tá ali naquele lugar, longe da minha família, aí resolvi vir embora.

Separação e reconciliação também foram vividas por três das mulheres entrevistadas e uma das razões apontadas é que os filhos permaneçam em contato com os pais, fato que pode ser utilizado para mascarar a dependência que têm do companheiro, tanto financeira, pois a mesma não trabalha, como afetiva.

E até hoje estamos juntos e não pretendo me separar mais, pois tenho minhas duas filhas pra tomar conta.

Uma vez ele foi embora, ele se separou passou uma semana e voltou pra casa (...).

Nenhuma separação ocorreu motivada pela infidelidade feminina ao contrário do que aconteceu em relação à masculina. Vale ressaltar que as mulheres, às vezes, ainda se responsabilizam pelo insucesso da relação e se sentem culpadas por não ter tido "competência" para manter a relação: (...) $\log o$ no começo foi bom, muito amor, eu gostava muito dele, mas depois eu fui desgostando assim com a traição do marido, foi aparecendo o que não devia mulher pra ele. Ele foi começando a sair de casa eu fui desconfiando, não acreditava mais nele, no que ele me dizia e infelizmente apareceu outra pessoa pra cuidar dele, que foi mais sabida do que eu e conseguiu ter ele.

Essa situação caracteriza as assimetrias de gênero que permeiam as relações conjugais, no grupo estudado, e dá visibilidade à posição de submissão a que essas mulheres estão sujeitas, determinadas por questões sociais, culturais e predominantemente econômicas. Essa relação de dominação masculina evidencia o poder 
exercido nas relações entre os sexos, visto que aos homens é dado o direito de trair e praticar atos violentos sem que isso acarrete em ônus para os mesmos. Um agravante, nessa condição, é que às mulheres resta conviver com a frustração do fracasso conjugal além do ônus da educação dos filhos e da provisão básica para os mesmos, tendo que retornar para suas famílias de origem, visto que a maioria se encontra fora do mercado de trabalho, condição agravada pela falta de qualificação profissional.

\section{CONSIDERAÇÕES FINAIS}

Observamos que no decorrer deste artigo não é possível separar gênero das condições de vida em que elas estão inseridas. Apesar da evidência de que o status da mulher está aumentando, com maiores possibilidades de inserção no mundo público, esta situação não pode ser generalizada, ficando grande parte das mulheres que vivem em uma situação de pobreza sem possibilidades de modificar a situação vivida, sem condições de enfrentar e dar basta as ocorrências de violência que sofrem.

O trabalho fora de casa seria um indicador de independência econômica, que poderia fortalecer a auto-estima que elas não têm. Essa mulher assume um papel perante a sociedade em que está inserida, de mãe e esposa, porém este papel traz consigo uma desigualdade de gênero em que o homem exerce um poder patriarcal inserido nessa sociedade e aceito por estas mulheres.

Elas vivem uma vida de desigualdade entre seus parceiros, sem condições econômicas ou emocionais de enfrentamento das infidelidades e agressões sofridas, pois devido as suas funções reprodutivas vivem uma divisão sexual do trabalho, tendo o seu dia-a-dia centrado na rotina doméstica, voltada para os cuidados com a casa, os filhos e o parceiro, ocupações tidas como femininas. Para modificar a situação de violência vividas por essa mulheres, é necessário romper com o ciclo de desigualdade em que estão inseridas, tanto de gênero como social.

\section{REFERÊNCIAS}

Badinter, E. (1993). X Y: La identidad masculina. Madrid: Alianza.

Badinter, E. (2004). Por mal caminho. Madrid: Alianza.

Bonzon, M. (1998). Demografia e sexualidade. En: M. A. Loyola, (Comp). Sexualidade nas ciências humanas. Rio de Janeiro: UERJ. p 227-251

Foucault, M. (2001). História da sexualidade: o uso dos prazeres. ( $9^{\mathrm{a}} \mathrm{ed}$ ) Rio de Janeiro: Ed. Graal.

Gregori, M. F. (1999). A transição da fecundidade e a violência contra a mulher. En: E Berquó. (Comp). Reflexões sobre gênero e fecundidade no Brasil. Campinas. Ed. Family Health Internnational. 15-22. Recuperado em 02 de abril de 2002 de http.//www.prossiga.br/fsp_usp/ saudereprodutiva.

Gomes, N. P., Diniz, N. M. F., Araujo, A. J. de S., \& Coelho, T.M.I. (2007). Compreendendo a violência doméstica a partir das categorias gênero e geração. Acta paul. enferm.,4, (20),504-508.

Minayo, M.C.de S. O. (2000). Ciência, técnica e arte: desafio da pesquisa social. En: Minayo, M.C.de S.O. (Comp). Pesquisa social: teoria, método e criatividade. (p.p. 9-29) Petrópoli:. Vozes.

Rosalvo, M. Z. (1979). A mulher, a cultura e a sociedade: uma revisão teórica. En: M.Z.

Rosalvo, \& L. Lamphere, (Eds) A mulher a cultura a sociedade. (p.p. 33-64). Rio de Janeiro: Paz e terra.

Saffioti, H. I. (2004).Gênero, patriarcado, violência. São Paulo: Fundação Perseu Abramo.

Salem, T. (2004). “Homem já viu, né?": representações sobre sexualidade e gênero entre homens da classe popular. En: M.L. Heilborn, Família e sexualidade. Rio de Janeiro: FGV. p 15-61

Secretaria Especial de Políticas para as Mulheres. (2006). Combate à violência contra a mulher ganha política nacional. Brasília: Ministério da Saúde.

Thompson, P. (1998). A voz do passado: história oral. ( $2^{\mathrm{a}}$ ed). Rio de Janeiro: Paz e Terra. 